\title{
Effects of the postsunset vertical plasma drift on the generation of equatorial spread $\mathrm{F}$
}

\author{
Chao-Song Huange
}

\begin{abstract}
Equatorial spread F (ESF) irregularities are caused by plasma instability processes in the equatorial ionosphere and especially related to plasma bubble phenomena in the topside $\mathrm{F}$ region. Plasma bubbles result from nonlinear evolution of the Rayleigh-Taylor instability. The prereversal enhancement (PRE) of the postsunset vertical plasma drift increases the height of the equatorial F layer, creating conditions conducive to the growth of the Rayleigh-Taylor instability, and is an important factor that controls the generation of ESF. Three different relationships of the quantitative connection between the PRE and ESF occurrence have been derived. (1) A threshold PRE must be reached for the occurrence of ESF. ESF will be generated when the PRE is larger than the threshold and will not be generated when the PRE is smaller than the threshold. (2) The occurrence probability of ESF increases approximately linearly with the PRE. (3) The occurrence probability of ESF is characterized by a continuous probability distribution as a function of the PRE magnitude. The second and third relationships imply that the PRE can be used to specify the occurrence probability of ESF. This paper will review these relationships and discuss how these relationships are connected to each other. The effects of seeding perturbations on the generation and global distribution of ESF will be briefly discussed.
\end{abstract}

Keywords: Equatorial ionosphere, Equatorial spread F, Plasma bubbles, Rayleigh-Taylor instability, Vertical plasma drift, Prereversal enhancement

\section{Introduction}

\section{The generation of ESF}

Equatorial spread F (ESF) stems from observations of the "spread" of the traces in equatorial ionograms and is used to describe plasma instability phenomena that occur in the equatorial $\mathrm{F}$ region ionosphere (Kelley 1989). The term, "plasma bubble," is used to describe a region within which the plasma density is significantly reduced in the nighttime equatorial ionosphere. Plasma bubbles result from nonlinear evolution of the RayleighTaylor instability that is excited in the bottom side of the equatorial $\mathrm{F}$ region. During the process of nonlinear growth of the instability, high-plasma density magnetic flux tubes at the bottomside of the ionospheric $\mathrm{F}$ region change places with lower density flux tubes from below, and the depleted magnetic fluxes finally rise to the

Correspondence: chaosong.huang.1@us.af.mil

Air Force Research Laboratory, Space Vehicles Directorate, 3550 Aberdeen Avenue S.E., Kirtland AFB, Kirtland, NM 87117, USA topside, forming plasma bubbles (Woodman and La Hoz 1976; Scannapieco and Ossakow 1976). Plasma density irregularities associated with bubbles (ESF irregularities) exist in both the bottomside and topside $\mathrm{F}$ regions.

The linear growth rate of the Rayleigh-Taylor instability is inversely proportional to the ion-neutral collision frequency. Since the neutral density in the atmosphere decreases exponentially with altitude (Kelley 1989), the ion-neutral collision frequency also decreases with altitude. The growth rate of the Rayleigh-Taylor instability becomes larger at higher altitudes because of smaller ion-neutral collision frequency there. High altitude of the bottomside $\mathrm{F}$ region is believed to be a necessary condition for the occurrence of ESF.

One process that can change the height of the equatorial F layer is the vertical plasma drift. The equatorial vertical plasma drift is, in general, upward during daytime and downward at night, and the reversal from upward to downward occurs around 2000 LT. An important feature 
of the equatorial F region vertical plasma drift is the occurrence of a sharp increase of the upward velocity just before it reverses to downward (Fejer et al. 1991, 2008). This prereversal enhancement (PRE) of the vertical plasma drift is associated with an enhanced eastward electric field when the E region conductivity decreases rapidly immediately after sunset. Large PRE often occurs around equinox when the geomagnetic field lines are aligned with the sunset terminator, so the eastward polarization electric field becomes the strongest near the sharp horizontal gradient of conductivity (Tsunoda 1985). Empirical patterns of the PRE and its dependence on solar radio flux, season, longitude, and geomagnetic activity have been derived from measurements of the Jicamarca incoherent scatter radar and satellites (Fejer et al. 1991, 2008).

In the postsunset sector, the PRE moves the equatorial F layer to high altitudes, and the bottomside of the $F$ layer becomes steeper than that in the daytime because of non-existence of photo-ionization there, creating conditions conducive to the growth of the Rayleigh-Taylor instability. Extensive efforts have been made to determine how the occurrence of ESF is quantitatively related to the PRE. Three different relationships have been derived, including (1) a threshold PRE for ESF occurrence, (2) linear increase of the ESF occurrence probability with the PRE, and (3) a continuous probability distribution of ESF occurrence as a function of the PRE. The objective of this paper is to provide a review of the current understanding of the relationship between the PRE and the generation of ESF.

\section{Definition of ESF irregularities}

ESF is one of the oldest scientific topics in the equatorial aeronomy. ESF phenomena were observed mostly with ionosonde in early studies. An ionosonde can be viewed as an HF sweep frequency radar which receives signals backscattered from regions where the transmitted frequency is near the electron plasma frequency. Booker and Wells (1938) observed diffuse echoes from the F region of the equatorial ionosphere over a wide range of wave frequency and suggested that the diffuse echoes were caused by irregularities in the ionospheric F region. The ionogram traces showed a range of virtual heights as if the echoing region were spread over a range of altitudes, which is termed range spread F. At other times, the spread occurred only at the high frequency end, which is termed frequency spread F. In most studies with ionosonde, spread $\mathrm{F}$ was identified when diffuse traces occurred in the ionogram. Abdu et al. (1983) used range spread $F$ index numbers, from 0 to 3 , to specify the degree of spreading in the ionogram, with zero representing the absence of spread F, 1 and 2 representing weak and moderate degrees of range spreading, and
3 representing severe spreading to the extent of making the virtual height reading impossible.

Incoherent and coherent scatter radars have been used to study ionospheric irregularities and structures. Farley et al. (1970) performed a study of spread F using the radar at Jicamarca and found that strong scattering from field aligned irregularities (spread F irregularities) completely masked the incoherent scatter data. Backscattered echoes from spread F irregularities can extend from bottomside to topside $\mathrm{F}$ region, forming ionospheric plumes (Woodman and La Hoz 1976). In radar observations, spread F was often identified from backscattered echoes. Recently, Smith et al. (2016) introduced two metrics, "ESF occurrence index" and "ESF maximum height," to describe ESF intensity. The first metric, ESF occurrence index, is defined as the percentage of bins between 1900 and 2400 LT and between 200 and $800 \mathrm{~km}$ altitude. The metric value is zero if ESF does not occur and 1 if ESF irregularities occur at all times between 1900 and 2400 LT and reach all altitudes in this time interval. The second metric is one based on the maximum height of the observed echoes, and the metric values range between 200 and $800 \mathrm{~km}$ or 0 (no ESF at all).

Measurements from low-Earth orbit satellites have been widely used to study ESF phenomena. Figure 1 shows an example of measurements made by the Communication/Navigation Outage Forecasting System (C/NOFS) satellite. In Fig. 1a, the blue line depicts the magnetic equator, the red line represents the latitude of C/NOFS, and the dashed magenta line, labeled on the right, represents the altitude (in $\mathrm{km}$ ) of $\mathrm{C} / \mathrm{NOFS}$. The red line is very close to the blue line, indicating that $\mathrm{C} / \mathrm{NOFS}$ flew almost along the magnetic equator. Figure 1b shows the ion density along the satellite track, and the irregular structures represent ESF irregularities.

Two quantitative definitions of ESF irregularities based on satellite measurements have been used in previous studies. One definition is the standard deviation of ion density variations in logarithmic scale divided by the mean of ion density in logarithmic scale, given by

$$
\sigma(\%)=100 \times \frac{\left[\frac{1}{10} \sum_{i=1}^{10}\left(\log N_{i}-\log N_{0 i}\right)^{2}\right]^{1 / 2}}{\frac{1}{10} \sum_{i=1}^{10} \log N_{0 i}}
$$

In the studies of $\mathrm{Su}$ et al. (2006, 2008) with measurements of the ROCSAT-1 satellite, the 1-s averaged data of the ion density were used. The 1-s data were linearly detrended in a 10-s segment (corresponding to $\sim 70 \mathrm{~km}$ along the satellite track). $N_{i}$ and $N_{0 i}$ in Eq. (1) are the measured ion density and the linearly fitted value at the $i$ th data point, respectively. Kil et al. (2009), also using ROCSAT-1 data, used 100-s data $(\sim 700 \mathrm{~km}$ along the 


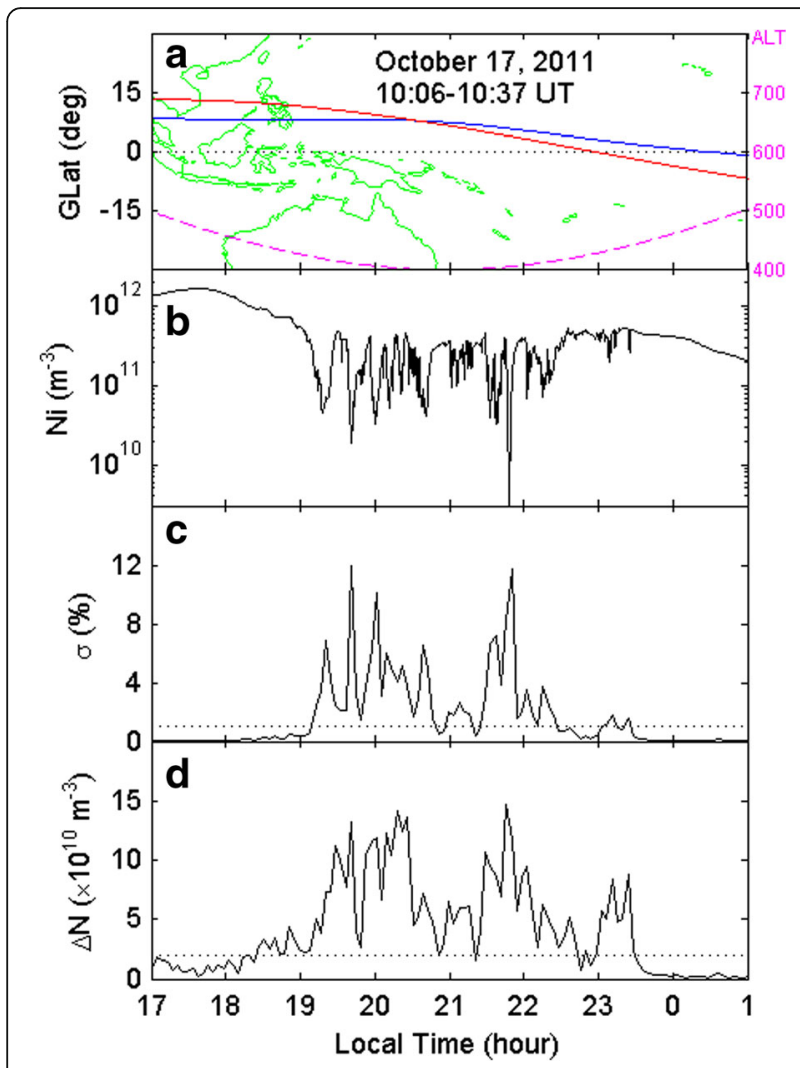

Fig. 1 Example of equatorial ionospheric irregularities measured by the Communication/Navigation Outage Forecasting System (C) NOFS) satellite on 17 October 2011. Figure 1 a-d show the C/NOFS orbit, the ion density, the standard deviation of ion density variations $(\sigma)$, and the ion density perturbations $(\Delta N)$, respectively

satellite track) instead of 10-s data, and the background ion density $\left(N_{0 i}\right)$ was represented by an 11-point smoothing curve. In the study of Huang et al. (2014), the ion density data were measured by the Planar Langmuir Probe (PLP) onboard the C/NOFS satellite. The original PLP measurement was made at $512 \mathrm{~Hz}$. The ion density data used by Huang et al. (2014) were the 1-s averages over the 512 samples per second. In other words, the ion density data in the study of Huang et al. (2014) had temporal resolution of $1 \mathrm{~s}$. The $\sigma$ value is calculated over 10 data points $(10 \mathrm{~s})$. Each $N_{i}$ is the ion density at the $i$ th data point, and each $N_{0 i}$ is the average value over $60 \mathrm{~s}$ (corresponding to $420 \mathrm{~km}$ along the satellite track) centered at the $i$ th data point. Two earlier studies (Kil and Heelis 1998; McClure et al. 1998) used $\sigma=\Delta N_{i} / \overline{N_{0 i}}$ to define ESF but did not use the 10-point average. Occurrence of ESF is identified with $\sigma>0.3$ or $\sigma>1 \%$.

Another definition of ESF irregularities is the absolute perturbation of the ion density, given by

$$
\Delta N=\left[\frac{1}{10} \sum_{i=1}^{10}\left(N_{i}-N_{0 i}\right)^{2}\right]^{1 / 2}
$$

In the studies of Huang et al. (2014) and Huang and Hairston (2015) using C/NOFS data, the method for the calculations of $\Delta N$ is the same as that for $\sigma$.

Both $\sigma$ defined by Eq. (1) and $\Delta N$ defined by Eq. (2) can be used to characterize plasma density perturbations for ESF occurrence. When the background plasma density is high, especially in the evening sector during the periods of high solar radio flux, the global distributions of ESF occurrence based on the two definitions are similar. Significant difference in the global distributions occurs when the background plasma density is low, for example, in the postmidnight sector near June solstice at deep solar minimum (Huang et al. 2014). The global distribution of ESF occurrence based on $\Delta N$ with C/NOFS data at moderate solar activity is quite similar to that based on $\sigma$ with ROCSAT-1 data (Kil et al. 2009).

Woodman and La Hoz (1976) proposed that the ionospheric plumes (ESF echoes) measured by the Jicamarca radar were caused by the plasma Rayleigh-Taylor instability. The numerical simulations of Scannapieco and Ossakow (1976) verified that the ionospheric plasma instability can indeed evolve into plasma bubbles. Sultan (1996) derived the linear growth rate of the RayleighTaylor instability:

$$
\gamma=\frac{\Sigma_{P}^{F}}{\sum_{P}^{E}+\Sigma_{P}^{F}}\left(V_{P}-U_{L}^{P}-\frac{g_{e}}{v_{\mathrm{eff}}^{F}}\right) K^{F}-R_{T}
$$

where $\Sigma_{P}^{E}$ and $\Sigma_{P}^{F}$ are the flux tube integrated $\mathrm{E}$ and $\mathrm{F}$ region Pedersen conductivities, $V_{P}$ is the flux tube integrated plasm velocity perpendicular to the magnetic field, $U_{L}^{P}$ is neutral wind in the geomagnetic meridional plane, $g_{e}$ is the effective gravity, $v_{\text {eff }}^{F}$ is the effective $\mathrm{F}$ region collision frequency weighted by number density along the flux tube, $K^{F}$ is the $\mathrm{F}$ region flux tube electron content height gradient, and $R_{T}$ is the flux tube recombination rate.

As can be seen from Eq. (3), the vertical plasma drift contributes to the growth rate of the Rayleigh-Taylor instability through different processes. Besides the direct contribution by $V_{B}$ an upward plasma drift moves the $\mathrm{F}$ layer to higher altitudes and increases the growth rate by causing a decrease in $v_{\text {eff }}^{F}$ and in $R_{T}$. Other two factors, the neutral wind and the ion-neutral collision frequency, also affect the growth rate of the instability.

In Eq. (3), the term $\left(-g_{e} / v_{\text {eff }}^{F}\right)$ is positive because of the downward gravity. $K^{F}$ is positive in the bottomside $\mathrm{F}$ region and negative in the topside $\mathrm{F}$ region. If we do not consider the plasma drift velocity, neutral wind, and recombination, the linear growth rate of the 
Rayleigh-Taylor instability is positive in the bottomside $\mathrm{F}$ region and negative in the topside $\mathrm{F}$ region. Farley et al. (1970) discussed the possible mechanisms for the generation of plasma irregularities in the equatorial topside $\mathrm{F}$ region and concluded that none of the linear theories of plasma instabilities (including the gravitational RayleighTaylor instability) that had been put forward to explain the occurrence of ESF could explain the observations. The Rayleigh-Taylor instability must evolve into the nonlinear regime to reach the topside $\mathrm{F}$ region, as illustrated by Woodman and La Hoz (1976) and simulated by Scannapieco and Ossakow (1976).

The Rayleigh-Taylor instability must be initiated in the bottomside $\mathrm{F}$ region by some perturbations in the ionosphere or thermosphere before it grows into plasma bubbles or topside ESF irregularities. Two types of seeding perturbations have been proposed. One is atmospheric gravity wave, and the other is large-scale wave structure, a structure in the ionospheric plasma density. Shear flow in the lower $\mathrm{F}$ region of the equatorial ionosphere could be the source of large-scale waves or Kelvin Helmholtz instabilities (Hysell and Kudeki 2004). In numerical simulations, the initial condition is often a perturbation in the plasma density, with an amplitude of 1-5\% (Scannapieco and Ossakow 1976; Zalesak et al. 1982), or a gravity wave. In the simulations of gravity wave seeding (Huang and Kelley 1996a, 1996b; Krall et al. 2013), the only initial perturbation for the Rayleigh-Taylor instability is a gravity wave, the first-order perturbation in the neutral velocity, and no initial perturbation in the plasma density is required. The gravity wave is to seed the Rayleigh-Taylor instability but does not contribute to the linear growth rate of the instability (see Huang and Kelley 1996a, 1996b for details).

Although initiation by a gravity wave seems likely, the gravity wave interaction cannot yield the large displacements observed without further amplification by the Rayleigh-Taylor instability, as suggested by Kelley et al. (1981, 1986). The simulations of Huang and Kelley (1996a, 1996b) and Krall et al. (2013) have demonstrated the formation of plasma bubbles seeded by gravity waves. Seeding by large-scale wave structure was proposed by Tsunoda (2005). Observational evidence of large-scale wave structure and its possible role in the generation of ESF irregularities was reported by Tsunoda and White (1981) and Thampi et al. (2009). Although ESF irregularities and plasma bubbles appear to be periodic sometimes (e.g., Huang et al. 2013), they are irregular and not periodic in most cases (e.g., Huang et al. 2012). Choi et al. (2017) analyzed C/NOFS data and found that a representative periodicity does not exist in the occurrence of bubbles and that the bubble spacing is generally irregular. Seeding perturbations for the Rayleigh-Taylor instability do not have to be periodic. Perturbations in the thermosphere and ionosphere, large scale or small scale, periodic or non-periodic, regular or irregular, can all initiate the Rayleigh-Taylor instability.

\section{Threshold PRE for the generation of ESF}

Because the vertical plasma drift is an important factor controlling the height of the $\mathrm{F}$ layer in the postsunset sector, investigators tried to determine how large the postsunset vertical plasma drift must be for the generation of ESF. An early effort made by Abdu et al. (1983) used ionosonde measurements to study the relationship between the PRE and the indices of range spread F. Occurrence of ESF was identified from diffuse traces in ionograms, and the vertical ionization drift velocity was derived from the change of the virtual height of the bottomside $\mathrm{F}$ layer with time, read from ionograms taken at 15 min intervals. About 100 events were used in the analysis. It was found that spread $\mathrm{F}$ would occur only when the vertical drift in the evening exceeded a threshold value of $\sim 17 \mathrm{~m} / \mathrm{s}$.

Using the rate of change of the virtual height of the $F$ layer with time to represent the vertical $\mathbf{E} \times \mathbf{B}$ drift requires that the change must be fast, which is largely met near the interval of the PRE. The most accurate measurement of ionospheric plasma drifts is made by incoherent scatter radar, such as the one at Jicamarca. Basu et al. (1996) conducted an equatorial campaign to investigate the neutral and plasma dynamics in the equatorial ionosphere. The Jicamarca radar was used to measure the vertical plasma drift through incoherent scatter measurements and the 3-m plume structures (ESF) through radar interferometer measurements, and radio wave scintillation caused by ESF irregularities was monitored at multiple ground stations. It was found that no ESF and scintillation were observed on two nights when the postsunset enhancement of upward plasma drift was absent and that ESF and scintillation were observed on other five nights preceded by the postsunset enhancements. They concluded that the PRE of $\sim 20 \mathrm{~m} / \mathrm{s}$ is a necessary condition for the generation of ESF.

Another study on the relationship between the magnitude of the vertical $\mathbf{E} \times \mathbf{B}$ drift velocity enhancement just after sunset and the occurrence of scintillation was made by Anderson et al. (2004). The $\mathbf{E} \times \mathbf{B}$ drift was derived from the height rise of the $4 \mathrm{MHz}$ contour between 1830 and 1930 LT measured by a digisonde at Jicamarca, Peru, and the scintillation S4 index was observed an hour or two later by scintillation receivers at Ancon, Peru, and Antofagasta, Chile. They found that the S4 index was generally less than 0.5 if the $\mathbf{E} \times \mathbf{B}$ drift velocity was less than $20 \mathrm{~m} / \mathrm{s}$ but greater than 0.5 when the $\mathbf{E} \times \mathbf{B}$ drift exceeded $20 \mathrm{~m} / \mathrm{s}$. They suggested that a "threshold" vertical drift velocity of $20 \mathrm{~m} / \mathrm{s}$ in the postsunset equatorial ionosphere 
determined whether or not the subsequent S4 values after 2000 LT would be below or above 0.5 .

The threshold vertical drift for ESF occurrence may vary with solar activity and season because the postsunset vertical plasma drift depend on ionospheric and thermospheric parameters that are affected by solar activity. Fejer et al. (1999) made a statistical analysis, based on measurements of the Jicamarca radar from 1968 to 1992, to study the effects of the PRE on the generation of ESF and to determine the dependence of the threshold PRE values on season, solar cycle, and magnetic activity. In the observations, strong spread $\mathrm{F}$ echoes from broad unstable regions occurred after large upward evening drifts, and weak echoes from a shorter lived and narrower altitude unstable layer occurred following smaller upward evening drifts. Figure 2 shows the results attained from over 200 evening and nighttime periods, and the peak values of the PRE are plotted as a function of the $10.7 \mathrm{~cm}$ solar radio flux for three seasons. From top to bottom in Fig. 2 are the results for equinox (March, April, September, and October), December solstice (November, December, January, and February), and June solstice (May, June, July, and August). For a given season and solar flux level, strong ESF events are generally associated with larger PRE drifts. The threshold drift velocity for the generation of strong evening ESF increases linearly with the solar flux, from 5 to $10 \mathrm{~m} / \mathrm{s}$ near solar minimum to $50-60 \mathrm{~m} / \mathrm{s}$ at the solar flux level of 250 . Effects of geomagnetic activity on ESF was also analyzed in this study, and it was found that extended geomagnetic activity during equinox at solar maximum causes large reductions in the amplitude of PRE, resulting in inhibition of the occurrence of ESF.

A more quantitative analysis of ESF was made by Smith et al. (2016), using measurements of the Jicamarca radar between 1994 and 2013. Smith et al. (2016) introduced "ESF occurrence index" and "ESF maximum height," as described in the section on "Definitions of ESF irregularities," to quantify the ESF strength and its relationship with the evening vertical plasma drifts. Figure 3 shows the ESF occurrence index as a function of the PRE peak drift for different seasons and solar flux levels. During equinox and December solstice, the PRE peak drifts are small (0$20 \mathrm{~m} / \mathrm{s}$ ) at low solar flux conditions and become larger $(20-50 \mathrm{~m} / \mathrm{s})$ at high solar conditions. Large PRE peak drifts are associated with high ESF occurrence index. Significant ESF with the occurrence index of $>0.1$ occurs when the PRE peak drifts are greater than $\sim-5 \mathrm{~m} / \mathrm{s}$ for December solstice and $\sim 5 \mathrm{~m} / \mathrm{s}$ for equinox during low solar flux, greater than $\sim 20 \mathrm{~m} / \mathrm{s}$ for December solstice and $\sim 15 \mathrm{~m} / \mathrm{s}$ for equinox during moderate solar flux, and greater than $\sim 25 \mathrm{~m} / \mathrm{s}$ for December solstice and $\sim 30 \mathrm{~m} / \mathrm{s}$ for equinox during high solar flux. Smith et al. (2016) suggested that their results tend to agree with the hypothesis of a threshold PRE for conditions leading to ESF
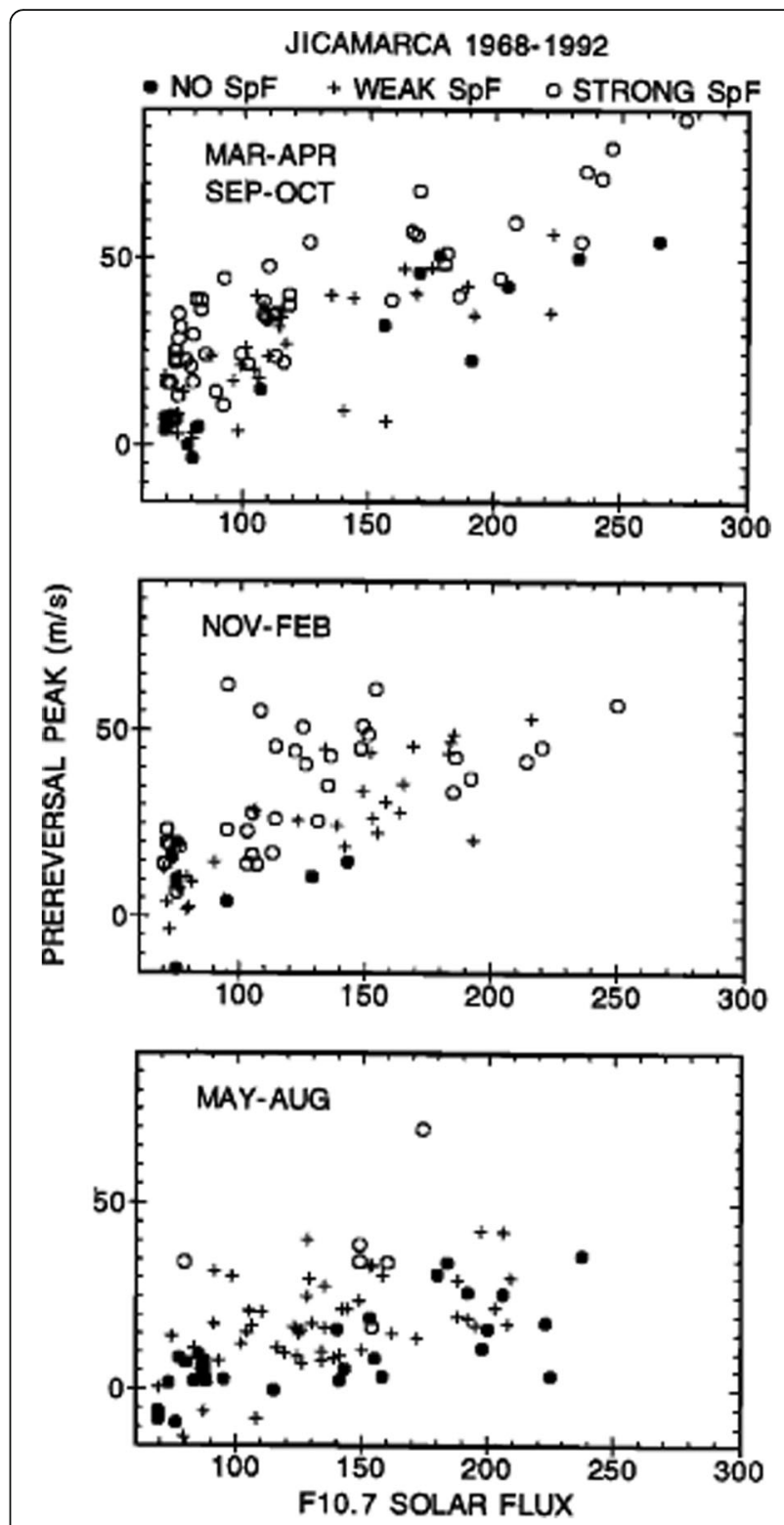

Fig. 2 Seasonal and solar cycle dependence of postsunset maximum upward drifts and spread F occurrence measured by the Jicamarca radar. Dots, plus signs, and open circles represent no spread F, weak spread F, and strong spread F events, respectively. (After Fejer et al. 1999)

development and that the threshold varies with solar flux and season.

The upward plasma drift moves the F layer to higher altitude (Fejer et al. 1999), so the threshold PRE could be related to a critical height of the F layer for ESF occurrence. Jayachandran et al. (1993) used HF Doppler radar and ionosonde measurements to determine the height and its variation of the evening equatorial $\mathrm{F}$ layer, the vertical plasma drift velocity in the evening equatorial region, and the occurrence of spread $F$. The observations showed that, for the onset of ESF, the F layer should attain 


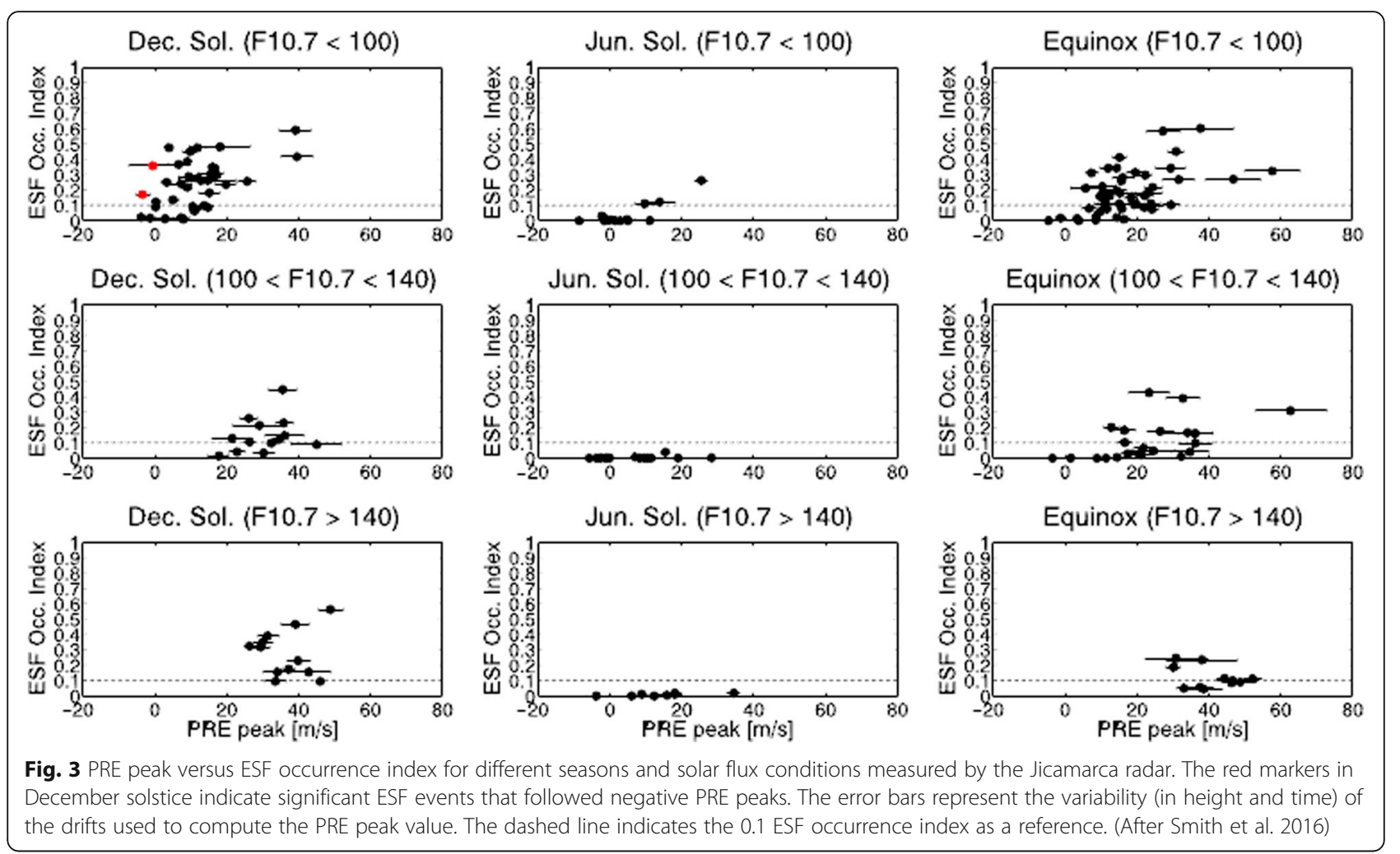

a threshold height. The threshold (group) height of the layer at $5.5 \mathrm{MHz}$ was $\sim 450 \mathrm{~km}$ at mean solar flux of 120 and $\sim 350 \mathrm{~km}$ at mean solar flux of 70 , and the corresponding evening peak upward drift velocities were 30 and $20 \mathrm{~m} / \mathrm{s}$, respectively. Dabas et al. $(1998,2003)$ observed the occurrence of VHF scintillation at low latitudes and spread $\mathrm{F}$ activity in equatorial regions. It was found that scintillations and spread $F$ occurred whenever the virtual height of the $\mathrm{F}$ layer, $h^{\prime} F$, rose to levels of more than $400 \mathrm{~km}$ during evening hours and that no scintillations were observed whenever $h^{\prime} F$ was less than $400 \mathrm{~km}$. The corresponding vertical $\mathbf{E} \times \mathbf{B}$ drift, derived from the change of the virtual height of the F layer, was $25-30 \mathrm{~m} / \mathrm{s}$ when scintillation was observed. Chapagain et al. (2009) used Jicamarca radar measurements from 1996 to 2006 to study the height of the equatorial $\mathrm{F}$ layer for the onset of ESF. They found that the onset heights increase linearly from about 260 to $400 \mathrm{~km}$ as the solar flux index increases from 60 to 250 and that higher onset heights generally lead to stronger radar echoes. Near solar minimum, the average onset heights of both weak and strong ESF are nearly the same, but for higher solar flux conditions, the onset heights of strong ESF events are generally higher by $\sim 20 \mathrm{~km}$.

Observations show that the threshold PRE for ESF occurrence, as well as the onset height of ESF, increases with the solar flux. Two factors may be responsible for this variation. One is the competition of the evening upward drift and the downward drift after the reversal, as discussed by Fejer et al. (1999). Near solar maximum, the evening upward drifts are large, but the downward drifts after the reversal are also large. The Rayleigh-Taylor instability must grow rapidly, reach the strongly nonlinear regime, and rise into the topside $F$ region under the effect of the internal polarization electric fields during the period of upward drifts before it is damped by enhanced ionneutral collisions as the large downward drift moves the $\mathrm{F}$ layer to lower altitudes. Another factor is the neutral density in the atmosphere that increases with the solar flux (Kelley 1989). The ion-neutral collision frequency at a fixed altitude becomes larger at higher solar flux, and the growth rate of the Rayleigh-Taylor instability becomes lower. As can be seen in Eq. (3), an increase in $V_{P}$ will compensate for the effects of enhanced ion-neutral collision frequency. Therefore, larger upward plasma drifts in the evening sector are needed to increase the height of the $\mathrm{F}$ layer at higher solar activity to generate strong spread $\mathrm{F}$.

The above studies established the notion of a threshold ESF for ESF occurrence. Some studies had only a limited events to show that ESF occurs when the PRE is large enough, and other studies had hundreds of events to confirm that larger PRE tends to more reliably produce ESF. However, the vertical plasma drift is not the only factor that affects the growth rate of the Rayleigh- 
Taylor instability. As can be seen in Eq. (3), the ionneutral collision frequency and neutral wind also contribute to the growth rate. While the PRE is an indicator of ESF, the contribution of other factors needs to be considered unless the plasma velocity $V_{P}$ becomes completely dominant.

\section{Linear increase of the ESF occurrence probability with the PRE}

In the scenario of a threshold PRE for ESF occurrence, the PRE must reach a minimum value (the threshold) for the generation of ESF. In other words, ESF will be generated if the PRE is larger than the threshold or not be generated if the PRE is smaller than the threshold. However, observations show that for a given PRE, the ESF strength could be significantly different. For example, the range spread $\mathrm{F}$ index varied from zero (no spread F) to two (moderate spread F) for a vertical drift at $22 \mathrm{~m} / \mathrm{s}$ and from 0.3 (almost no spread F) to 2.4 (moderate to strong spread F) for a vertical drift at $33 \mathrm{~m} / \mathrm{s}$ (Abdu et al. 1983). In some other cases, no spread $\mathrm{F}$ was observed even when the PRE was large (Huang and Hairston 2015), and strong ESF was observed when the PRE was nearly zero (Huang and Hairston 2015; Smith et al. (2016)). These observations indicate that ESF might not occur even if the PRE reached the threshold and that ESF could occur even if the PRE was smaller than the threshold.

The occurrence probability of ESF as a function of season and longitude has been derived from satellite data. Different amplitudes of $\sigma$ were used to identify the occurrence of ESF, including $\sigma>0.3 \%$ (McClure et al. 1998, Su et al. 2006, 2008, Kil et al. 2009) and $\sigma>$ 1.0\% (Kil and Heelis 1998, Huang et al. (2014). At any season and longitude, occurrence of ESF is probable although the probability depends on season and longitude. Because the PRE is a major factor that affects the generation of ESF, the occurrence probability of ESF may depend on the PRE.

Whalen (2003) analyzed the maximum electron density of the postsunset equatorial anomaly, ESF occurrence, and the peak value of the PRE from multiple data sources. Data of electron density were taken from the measurements of an array of ionospheric sounders during the International Geophysical Year in 1958 at solar maximum, and equatorial plasma bubbles were identified as range spread $\mathrm{F}$ from other instruments. No direct measurement of the vertical plasma drifts was available during the same period. Instead, plasma drifts at the peak PRE measured by the Jicamarca incoherent scatter radar during 19681992 by Fejer et al. (1999) were used to compare with the measurements of the ionospheric sounders during 1958. The electron densities at Bogota at $16^{\circ}$ and at Panama at $20.3^{\circ}$ dip latitude near the anomaly crest, the occurrence of ESF near the magnetic equator, and the peak drifts of the PRE over Jicamarca were binned at two different Kp levels over three seasons (equinox, December solstice, and June solstice). It was found that the electron density at the anomaly increases linearly with the PRE peak drift and that the occurrence of ESF increases linearly with the anomaly electron density during equinox and June solstice. Based on these relationships, it was proposed that the occurrence of ESF is dependent on the PRE and increases approximately linearly with the PRE.

Li et al. (2007) used measurements from the Defense Meteorological Satellite Program (DMSP) and ROCSAT1 satellites during a period of three years (2000-2002) near solar maximum to investigate the longitudinal/seasonal dependence of plasma bubble occurrence on the postsunset vertical plasma drift. The DMSP satellites had polar orbits at $840 \mathrm{~km}$. The ROCSAT-1 satellite was in a circular orbit at $600 \mathrm{~km}$ with an orbit inclination of $35^{\circ}$. The occurrence of ESF was identified from ion density data when $\sigma$, defined by Equation (1), is larger than $0.3 \%$. For DMSP data, the vertical ion drift measured at $1800 \mathrm{LT}$ was used to represent the PRE. For ROCSAT-1 data, the vertical ion drift between 1800 and 1900 LT was used to represent the PRE. In both DMSP and ROCSAT-1 data, the mean value of vertical drift velocities within $\pm 5^{\circ}$ from the magnetic equator is used to represent the vertical drift over the magnetic equator. The PRE value used in this study was not the peak drift of the PRE. It was found that the longitudinal/seasonal variations of plasma bubbles occurrence are similar to those of the PRE and that higher occurrence of plasma bubbles is related to larger PRE values. It was suggested that the occurrence probability of equatorial plasma bubbles is closely related to the pre-reversal $\mathbf{E} \times \mathbf{B}$ drift.

Su et al. (2008) also used ROCSAT-1 data during 19992004 to study the dependence of the ESF occurrence probability on the postsunset vertical plasma drift and the same the methodology as used by Li et al. (2007). Su et al. (2008) used the mean value of the ion vertical drifts within $\pm 5^{\circ}$ dip latitudes between 1800 and 1900 LT to represent the vertical drift over the magnetic equator. The occurrence of ESF irregularities with $\sigma \geq 0.3 \%$ within $\pm 15^{\circ}$ dip latitudes was derived during magnetic quiet times in the local time range of $1800-2400 \mathrm{~h}$. The data were separated into four seasons, and the results are shown in Fig. 4.

The gray horizontal lines in Fig. 4 represent the range over which the postsunset vertical ion drift may vary for a given occurrence probability. In each panel (each season), the solid line represents the linear regression of the data, an empirical formula of the ESF occurrence probability as a function of the vertical drift is derived from the linear regression, and $\rho$ is the correlation coefficient between the vertical drift velocity and the irregularity occurrence rate. The highest correlation occurs during the December solstice season (November, December, and January), and the 


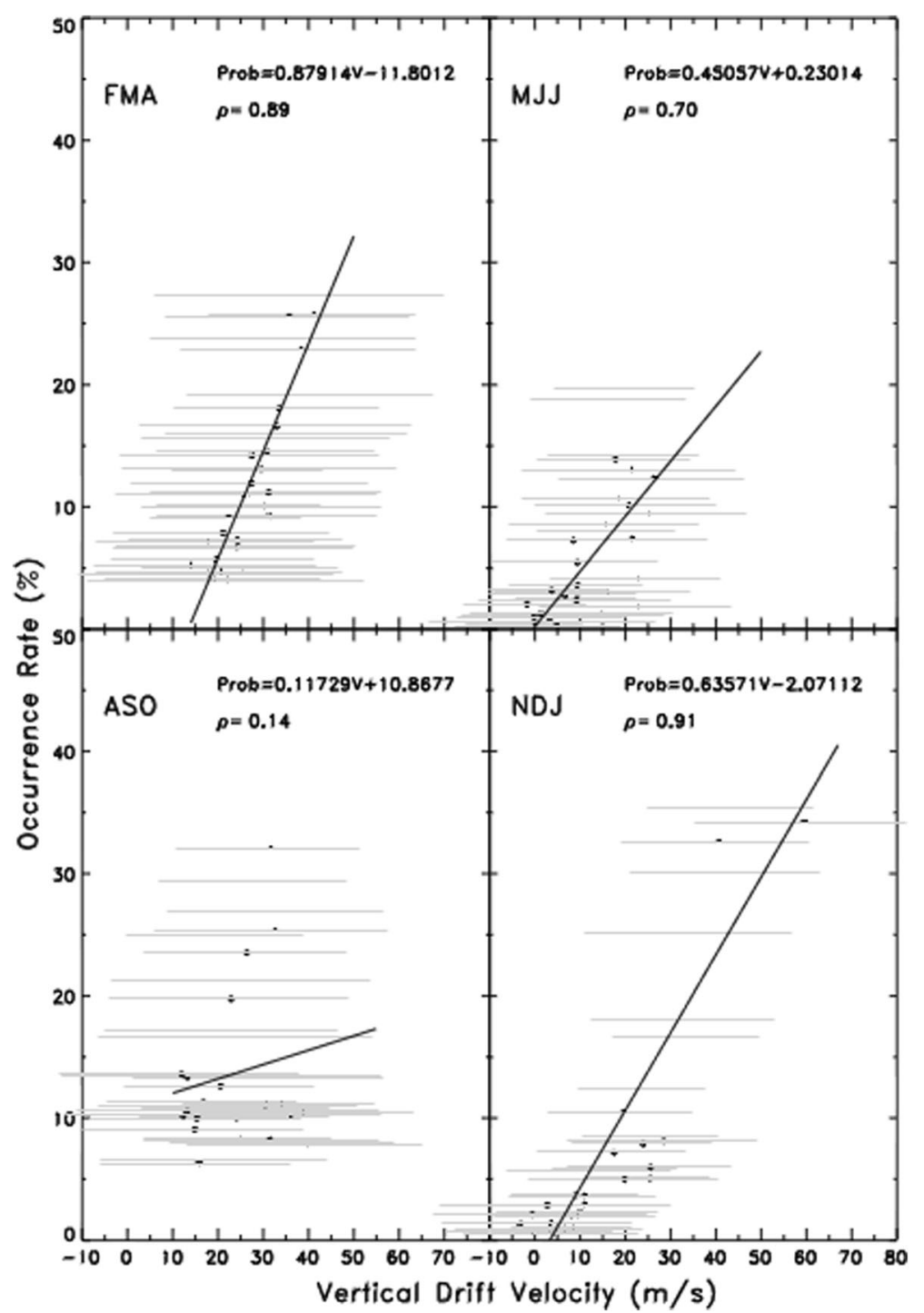

Fig. 4 Linear regression analysis of the topside vertical ion drift velocities between 1800 and 1900 LT with the ESF irregularity occurrence rates measured by the ROCSAT-1 satellite. (After Su et al. 2008)

lowest correlation occurs during the September equinox (August, September, and October). Su et al. (2008) concluded that the vertical drift velocities at three different longitude zones of magnetic declination have good correlations with the irregularity occurrences for all seasons and that the averaged postsunset vertical drift velocity is a good indicator for the occurrences of equatorial density irregularities in a longitude region of similar magnetic declination.

A similar analysis on the occurrence probability of ESF irregularities associated with plasma bubbles based on the measurements of the ROCSAT-1 satellite during 1999-2004 was performed by Kil et al. (2009). The vertical ion velocities within $\pm 5^{\circ}$ dip latitudes at $1730-1930$
LT were used to represent the PRE. The occurrence of ESF irregularities was identified with $\sigma \geq 0.3 \%$ when the satellite orbit was within $\pm 10^{\circ}$ dip latitudes between 2000 and 0000 LT. The global distributions of the PRE and the ESF occurrence probability are similar, indicating that the PRE is an important factor in the generation of plasma bubbles. Figure 5 presents the relationship between the bubble occurrence probability and the PRE, and the straight line represents the linear fitting of the data. The results show the presence of a linear relationship between the ESF/bubble occurrence probability and the magnitude of the PRE.

The three studies (Li et al. 2007; Su et al. 2008; Kil et al. 2009) all used data obtained by the ROCSAT-1 


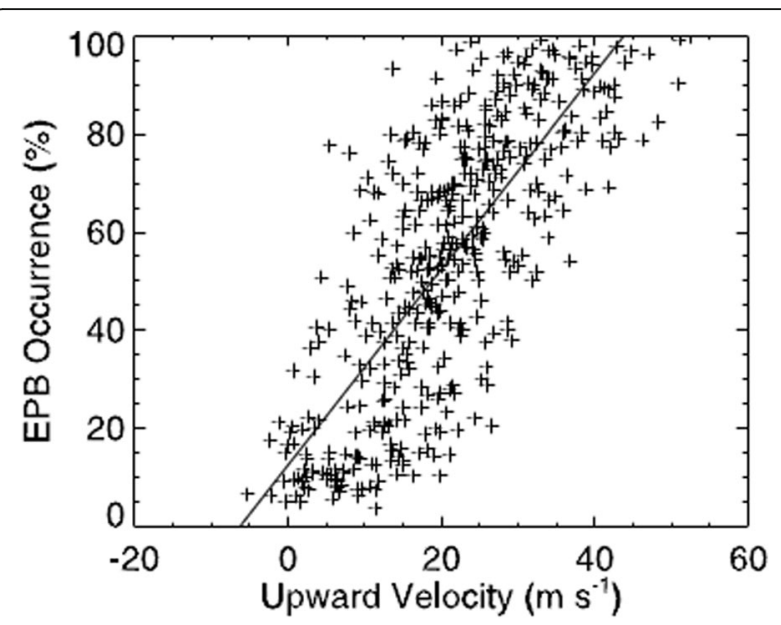

Fig. 5 Relationship between the plasma bubble occurrence probability and the topside vertical ion drift velocities between 1730 and 1930 LT measured by the ROCSAT-1 satellite. (After Kil et al. 2009)

satellite. The similarity in the conclusions of these studies is that the occurrence probability of ESF/plasma bubbles increases approximately linearly with the mean vertical drift over the interval of 1800-1900 LT or 1730-1930 LT. The difference is that the occurrence probability of ESF is low ( $<30 \%$ in most cases) even for the mean vertical drift at $\sim 60 \mathrm{~m} / \mathrm{s}$ in Su et al. (2008) but high $(\sim 100 \%)$ for the mean vertical drift at $\sim 40 \mathrm{~m} / \mathrm{s}$ in Kil et al. (2009). A possible cause for the difference is the method used to identify the occurrence of ESF. In the study of $\mathrm{Su}$ et al. $(2006,2008)$, the satellite transit time within a square grid of $1^{\circ}$ in longitude and latitude during a period of 5.5 years was recorded. The time duration with $\sigma>0.3 \%$ in a square grid was also recorded. The total time duration of the irregularity occurrence was then divided by the satellite transit time to obtain the occurrence probability in that square area. The seasonal/longitudinal distributions of the vertical plasma drifts near dusk (1800-1900 LT) and the ESF irregularity occurrences within $\pm 15^{\circ}$ dip latitudes in the evening sector (1800-2400 LT) were calculated separately, and the average values of the vertical plasma drifts and irregularity occurrences were then used to calculate the occurrence probability as a function of the vertical drift. In the study of Kil et al. (2009), presence of ESF (or plasma bubbles) on a given night was identified if plasma bubbles were detected between 1900 and 0600 LT within $\pm 10^{\circ}$ dip latitudes. The different methods used by Su et al. (2008) and Kil et al. (2009) resulted in the different levels of the occurrence probability of ESF.

\section{Continuous probability function of plasma bubble occurrence as a function of the PRE}

The scientific objective of the C/NOFS satellite was to understand the physical processes that lead to the formation of plasma bubbles and plumes in the nighttime equatorial ionosphere. C/NOFS was launched into a lowinclination $\left( \pm 13^{\circ}\right.$ in geographic latitude) orbit in April 2008 and reentered the atmosphere in November 2015. The apogee and perigee of C/NOFS were 850 and $400 \mathrm{~km}$ during 2008 and gradually reduced to 635 and $377 \mathrm{~km}$ in April 2014; the orbital period of C/NOFS was $\sim 100 \mathrm{~min}$. $\mathrm{C} / \mathrm{NOFS}$ regularly flew along, or close to, the magnetic equator over a large longitude/local time range and provided continuous measurements of ionospheric ion density and ion drift velocity for more than 7 years.

Figure 6 shows an example of C/NOFS measurements of ion density and vertical ion drift velocity during three successive orbits on 17 October 2011 (Huang and
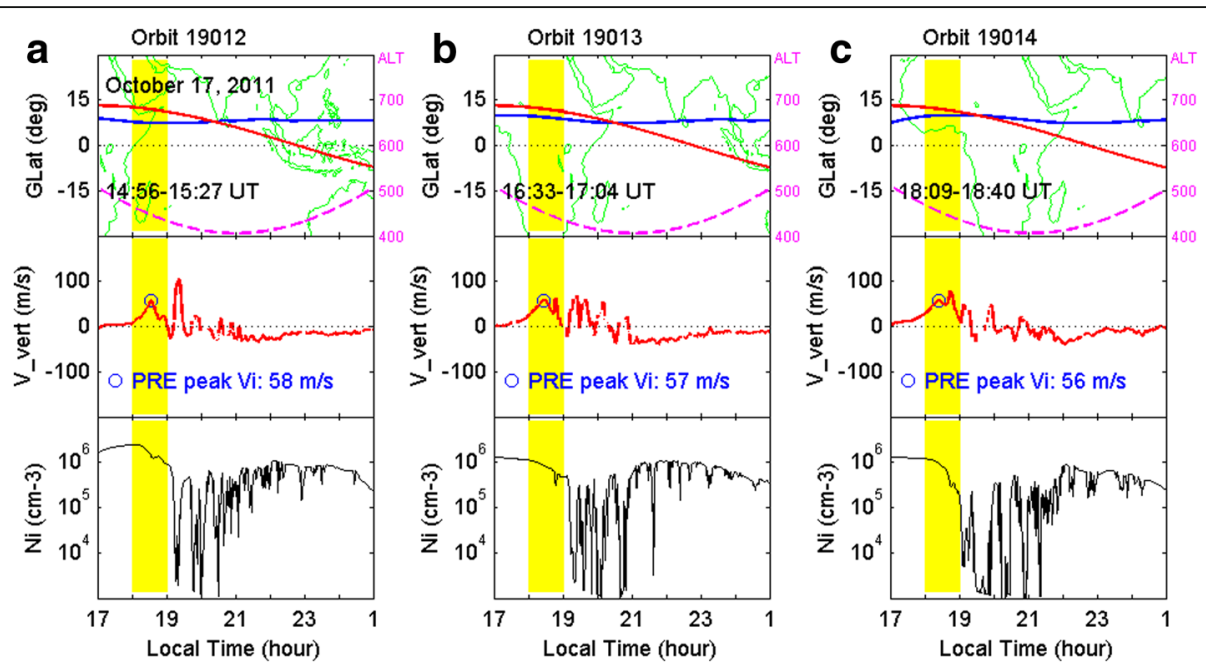

Fig. 6 Examples of plasma bubbles with large prereversal enhancement (PRE) detected by the C/NOFS satellite during three successive orbits (a, b, c) on 17 October 2011. From top to bottom are the C/NOFS orbit, the vertical ion drift velocity, and the ion density, respectively. (After Huang and Hairston 2015) 
Hairston 2015). The top row depicts the C/NOFS orbit. In the second row, the ion vertical velocity measured by the Ion Velocity Meter (IVM) onboard C/NOFS is plotted as a function of solar local time at the satellite position. In the IVM data, the meridional component of the ion drift velocity is defined to be in the direction perpendicular to the magnetic field lines in the meridian plane. In the study of Huang and Hairston (2015), the cases were selected when C/NOFS was within $\pm 5^{\circ}$ from the magnetic equator at $1800-1900 \mathrm{LT}$, as denoted by the yellow shading in Fig. 6. In this latitude range, the magnetic field lines are nearly horizontal, so the meridional component of the ion drift velocity is very close to the vertical component. Furthermore, since the geomagnetic field lines are almost equipotential, electric fields at large scales are nearly the same along the field lines over a limited distance. Therefore, the meridional ion drift within \pm $5^{\mathrm{o}}$ magnetic latitudes is nearly equal to the vertical ion drift over the magnetic equator.

C/NOFS took 31 min to fly through the local time range of $8 \mathrm{~h}(1700-0100 \mathrm{LT})$, that is, $\sim 4 \mathrm{~min}$ to fly over $1 \mathrm{~h}$ in local time. The variation of the vertical ion drift along the satellite's track in the middle row of Fig. 6 represents the distribution of the vertical ion drift with local time. The vertical ion drift showed a large increase at 1800-1900 LT in the shaded interval, and this increase is the PRE. The ion drift at the PRE peak is denoted by a blue circle. The PRE peak drifts were 58,57 , and $56 \mathrm{~m} / \mathrm{s}$ during the three orbits, respectively. Shown in the bottom row is the ion density. The deep depletions of the ion density are plasma bubbles. Spikes in the vertical ion drift after the PRE peak correspond to decreases in the ion density and are related to the polarization electric fields inside plasma bubbles.

A prominent feature in Fig. 6 is that deep density depletions (plasma bubbles) occurred after a large PRE. However, it should be mentioned that the PRE does not cause the generation of the plasma bubbles at later local times during the same orbit. In fact, the Rayleigh-Taylor instability starts to grow in the PRE interval. When this longitude region of the PRE rotates to the evening sector in the local time range of 1840-2100, measured during the next orbit, the instability evolves into plasma bubbles. That is, the PRE during Orbit 19,012 in Fig. 6a caused the plasma bubbles during Orbit 19,013 in Fig. $6 \mathrm{~b}$, and so on.

Huang and Hairston (2015) analyzed 2056 events, including 886 bubble events and 1170 non-bubble events, when $\mathrm{C} / \mathrm{NOFS}$ was within $\pm 5^{\circ}$ from the magnetic equator. An event of ESF/plasma bubble is defined to be the one with $\Delta N>1 \times 10^{10} \mathrm{~m}^{-3}$. Figure 7a shows the PRE peak $V_{i}$ as a function of day of year. In this figure, the term, the PRE peak $V_{i}$, is used to represent the vertical ion drift at the PRE peak, or the maximum vertical ion drift in the interval of 1800-1900 LT if there is no PRE or if the ion drift is negative (downward). The seasonal variation of the PRE peak $V_{i}$ is obvious. The occurrence probability of plasma bubbles is defined as the ratio of the bubble events to the total events in each velocity bin of $5 \mathrm{~m} / \mathrm{s}$ (e.g., $-2.5 \leq V_{i}<2.5$ and $2.5 \leq V_{i}<7.5$ ) and shown in Fig. $7 \mathrm{~b}$. The bubble occurrence probability is characterized by a continuous probability distribution as a function of the PRE peak $V_{i}$. The occurrence probability of plasma bubbles is very small when the ion drift is negative (downward), increases rapidly when the ion drift increases from 0 to $40 \mathrm{~m} / \mathrm{s}$, and reaches $80 \%$ or higher when the ion drift is greater than $40 \mathrm{~m} / \mathrm{s}$.

The occurrence probability of ESF irregularities/ plasma bubbles in Fig. 7b was derived from 2056 events, including all solar activity levels, seasons, and longitudes for the period of May 2008-June 2013. We now separate the data into three subsets for three seasons: Equinox (March, April, September, October), June solstice (May, June, July, August), and December solstice (November,
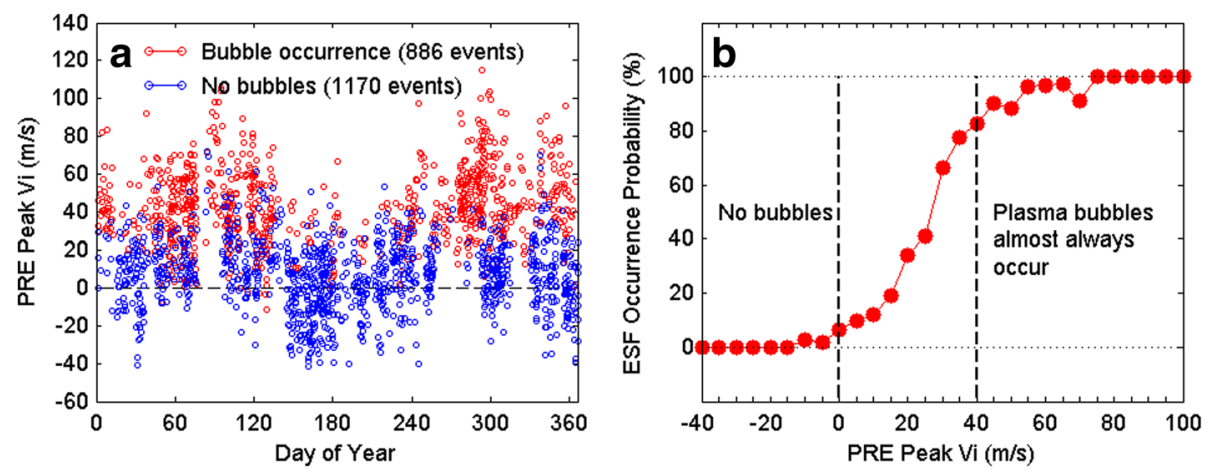

Fig. 7 a The vertical ion drift at the PRE peak in the cases with plasma bubbles (red circles) and in the cases without plasma bubbles (blue circles) detected by C/NOFS during May 2008-June 2013. b The dependence of the plasma bubble occurrence probability on the vertical ion drift at the PRE peak. (After Huang and Hairston 2015) 
December, January, February). The ESF occurrence probability in each season is calculated in the same method as the one for Fig. 7b, and the results are shown in Fig. 8. The distributions of the ESF occurrence probability are similar in different seasons. However, because of less events in each subset (on average, $~ 700$ events in each season), there are some subtle differences among the three seasons.

\section{Connection among the three relationships between the PRE and ESF occurrence}

The three relationships of the dependence of ESF occurrence on the PRE were discussed above. The first one is that there is a threshold PRE for the generation of ESF (Abdu et al. 1983; Basu et al. 1996; Fejer et al. 1999; Anderson et al. 2004; Smith et al. (2016)). In this scenario, ESF will either occur for a PRE of larger than the threshold or not occur for a PRE of smaller than the threshold. In contrast, the occurrence probability of ESF in other two relationships means that the occurrence probability of ESF depends on the PRE: linear increase of the ESF occurrence probability with the PRE (Su et al. 2008; Kil et al. 2009) or a continuous probability distribution as a function of the PRE (Huang and Hairston 2015). Occurrence of ESF is assured only for the PRE values where the occurrence probability is $100 \%$, and non-occurrence of ESF is assured only for the PRE values where the occurrence probability is zero. For all other PRE values, ESF may occur or not occur, although the probability for occurrence can be different.

There are some differences in the identification of the PRE and ESF between the linear increase of the ESF occurrence probability and the continuous probability distribution. In the studies of Su et al. (2008) and Kil et al. (2009), the PRE drift is the mean value of the vertical ion drift over $\sim 50 \mathrm{~min}$ in local time during 1800-1900 or $1730-1930 \mathrm{LT}$ and over $\pm 5^{\circ}$ in dip latitude but not the drift at the PRE peak, the PRE and ESF events were measured separately, without one-to-one correspondence, and a linear regression is used to represent the relationship between the PRE and ESF occurrence. In the study of Huang and Hairston (2015), the PRE peak $V_{i}$ is the drift at the PRE peak without any averaging in local time or latitude, one-to-one correspondence between the PRE during one orbit and the ESF event during next orbit is identified, and the ESF occurrence probability is defined as the ratio of the ESF events to total events in each velocity bin of $5 \mathrm{~m} /$ s. The linear relationship is based on data with $V_{i}$ mostly within $0-40 \mathrm{~m} / \mathrm{s}$ and could be altered if different regression techniques were used. As can be seen in Fig. 7b, the occurrence probability increases rapidly with the peak PRE drift between 0 and $40 \mathrm{~m} / \mathrm{s}$. When the occurrence of ESF is examined in a larger range of $V_{i}$, the continuous probability distribution is derived.

The threshold PRE for ESF occurrence could be related to the occurrence probability of ESF in the following ways. If we take a closer look at the data in Fig. 2, dots (no spread F), plus signs (weak spread F), and circles (strong spread F) all exist within some small range of the PRE and solar flux (e.g., $10 \mathrm{~m} / \mathrm{s}$ in the PRE drift and 50 units in the solar flux). In other words, ESF might occur or not occur in this range of the PRE and solar flux. In Fig. 3, especially the top row with more events, there is a trend that the cases with larger ESF occurrence index occur at higher PRE peak drift, implying that the PRE peak drifts (or the threshold drifts) are not exactly the same for the cases at different levels of the ESF occurrence index. The threshold PRE can be explained as that ESF almost certainly occurs if the PRE reaches the threshold. This is, in fact, equivalent to the statement that the occurrence probability of ESF is almost $100 \%$ for this PRE value. The occurrence probability of ESF is nearly $100 \%$ when the PRE peak drift is larger than $60 \mathrm{~m} / \mathrm{s}$ in Fig. 7b. These PRE values for near $100 \%$ occurrence probability in Huang and Hairston (2015) are close to the threshold PRE (50-60 m/s) for ESF occurrence at high solar flux (Fejer et al. 1999).
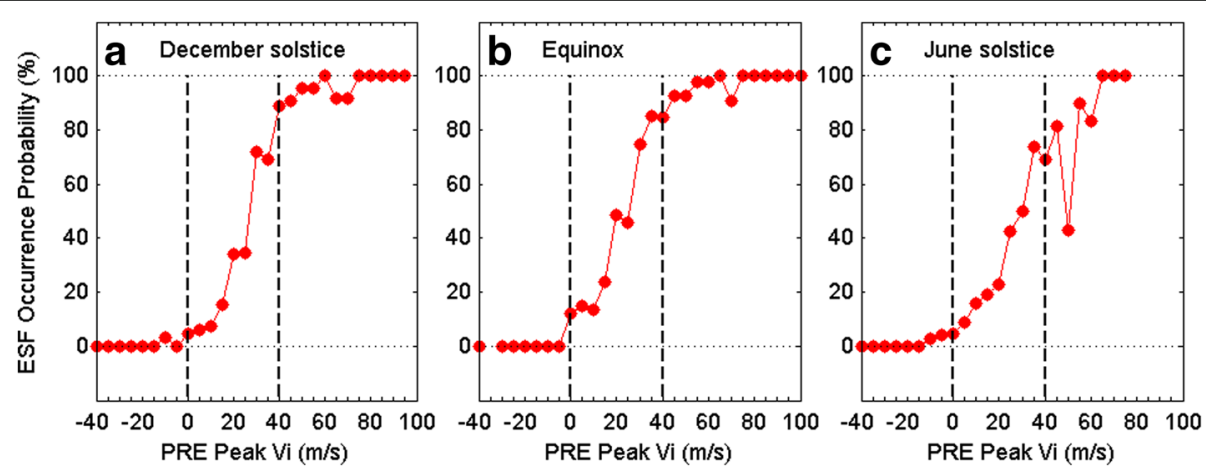

Fig. 8 The dependence of the plasma bubble occurrence probability on the vertical ion drift at the PRE peak measured by C/NOFS during May 2008-June 2013 for different seasons (a, b, c) 
Another factor for the two relationships (the threshold PRE and the occurrence probability) could be the number of events used in the studies. The threshold PRE was derived from a relatively small amount of events in ionosonde and radar measurements $(\sim 100$ events in Abdu et al. 1983, 10 events in Basu et al. 1996, 60 events in Anderson et al. 2004, 200 events in Fejer et al. 1999 and Smith et al. (2016)). If only a small number of events are used, it is likely to find that ESF occurs when the PRE is larger than some values. For example, Huang et al. [2012] analyzed C/NOFS data in 2 days and found that plasma bubbles were generated during 15 orbits when the PRE peak $V_{i}$ was $40-70 \mathrm{~m} / \mathrm{s}$. If we only examined these 15 events, the conclusion would be that plasma bubbles occurred when the PRE peak $V_{i}$ was larger than $40 \mathrm{~m} / \mathrm{s}$. The observations of these 15 events are consistent with the explanation of a threshold PRE for the generation of ESF. Huang and Hairston (2015) analyzed 2056 events, and they derived the continuous probability distribution of ESF/bubble occurrence as a function of the PRE peak $V_{i}$, as shown in Fig. 7b.

The threshold PRE for ESF occurrence is based on measurements of the Jicamarca incoherence scatter radar (Fejer et al. 1999; Smith et al. (2016)). The ESF occurrence probability as a function of the PRE is based on satellite measurements ( $\mathrm{Su}$ et al. 2008; Kil et al. 2009; Huang and Hairston 2015). When the radar data are compared with the satellite data for ESF occurrence, it should be mentioned that the measurements were made at different altitudes. In the radar measurements, weak spread F irregularities are those below the F peak, often below $400 \mathrm{~km}$, and strong spread $\mathrm{F}$ irregularities are those in the topside $\mathrm{F}$ region. In the satellite measurements, the altitudes were $\sim 600 \mathrm{~km}$ for ROCSAT- 1 and $400-800 \mathrm{~km}$ for C/NOFS, implying that ESF irregularities already reached the topside $\mathrm{F}$ region. Therefore, the ESF events based on the satellite measurements mostly correspond to the strong spread $F$ events based on the radar measurements. Another difference in the measurements is longitude. The radar data were obtained at a fixed longitude (Jicamarca). In contrast, the satellite data were obtained over all longitudes, and the dependence of the ESF occurrence probability on the PRE at some specific longitudes (e.g., Jicamarca) has not been determined from satellite data.

\section{Seeding effects on the generation of ESF}

The Rayleigh-Taylor instability must be initiated by some perturbations in the ionosphere or thermosphere before it grows into plasma bubbles or topside ESF irregularities, which is well understood and widely accepted. What is not well understood is whether the seeding perturbations affect the global distribution of ESF occurrence. We present in Fig. 9 the global distributions of the PRE and

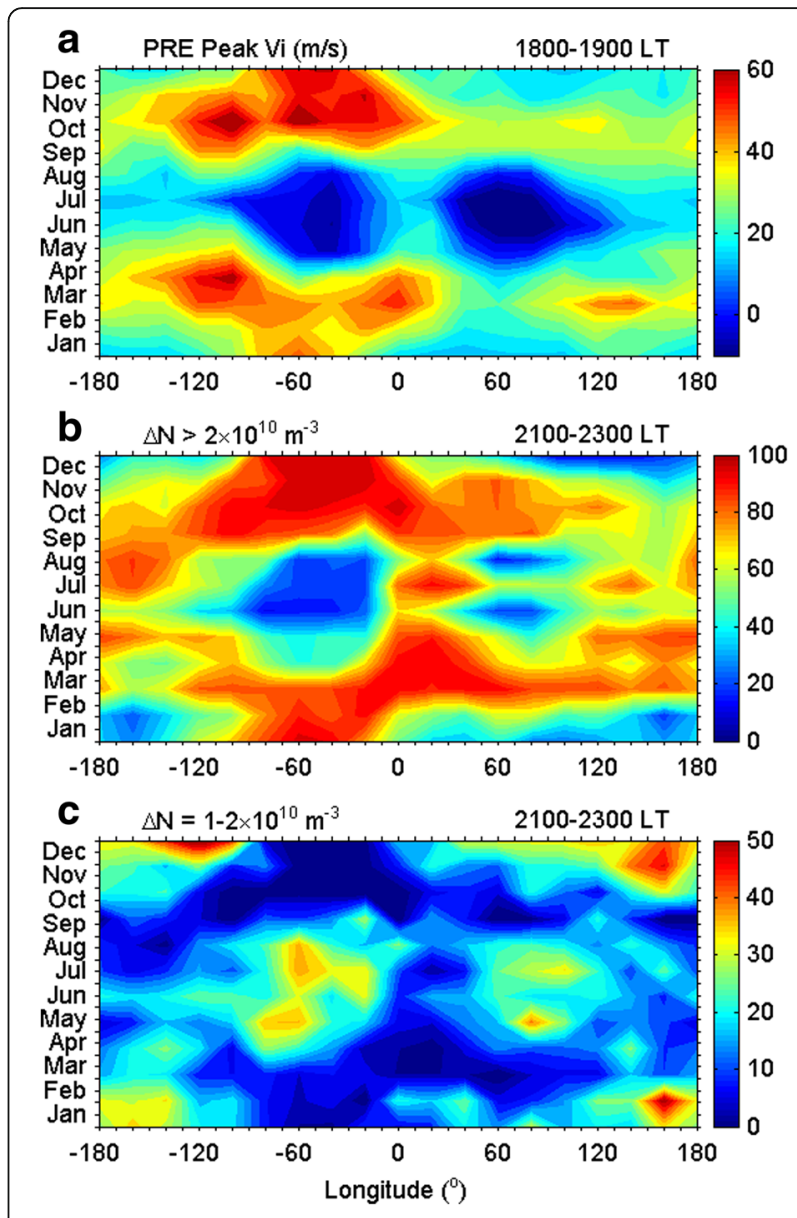

Fig. 9 The longitude-month distributions of $\mathbf{a}$ the vertical ion drift at the PRE peak, $\mathbf{b}$ the occurrence probability of large amplitude ESF irregularities with $\Delta N>2 \times 10^{10} \mathrm{~m}^{-3}$, and $\mathbf{c}$ the occurrence probability of small-amplitude ESF irregularities with $\Delta N=1-2 \times 10^{10} \mathrm{~m}^{-3}$ measured by C/NOFS during moderate solar activity in 2011-2014, respectively

the occurrence probability of evening ESF observed by $\mathrm{C} /$ NOFS within $\pm 10^{\circ}$ magnetic latitudes during the period of moderate solar activity in 2011-2014. The longitudemonth distribution of the PRE peak drifts is depicted in Fig. 9a. The PRE peak drift is large between $-180^{\circ}$ and $0^{\circ}$ longitudes at equinoxes and in December solstice and becomes very small or even downward around $\pm 60^{\circ}$ in June solstice. In Fig. 9b, c, ESF irregularities are calculated from ion density perturbations defined by Eq. (2). Largeamplitude ESF irregularities are defined to be the irregularities with $\Delta N>2 \times 10^{10} \mathrm{~m}^{-3}$, and small-amplitude ESF irregularities are those with $\Delta N$ in the range of $1-2 \times$ $10^{10} \mathrm{~m}^{-3}$. Figure $9 \mathrm{~b}, \mathrm{c}$ shows the longitude-month distributions of the occurrence probability of large-amplitude and small-amplitude ESF irregularities, respectively. A prominent feature is that the occurrence probability of small-amplitude ESF irregularities is anti-correlated with that of large-amplitude ESF irregularities and with that of the PRE peak drift. The months and longitudes with high- 
occurrence probability of large-amplitude ESF irregularities are exactly those with low-occurrence probability of smallamplitude ESF irregularities and vice versa. Large PRE peak drift corresponds to high-occurrence probability of largeamplitude ESF irregularities but to low-occurrence probability of small-amplitude ESF irregularities.

In the regions of large vertical plasma drift, the growth rate of the Rayleigh-Taylor instability is high, and the instability can rapidly grow into plasma bubbles, producing large-amplitude irregularities. In other regions with small vertical plasma drift or downward drift, the growth rate of the Rayleigh-Taylor instability is low, and the instability may not be able to grow into fully developed plasma bubbles and may only produce plasma irregularities with relatively small amplitude. The high growth rate of the Rayleigh-Taylor instability in the regions of large PRE results in the correlation between the PRE and the occurrence probability of large-amplitude irregularities, and the low growth rate of the instability in the regions of small or negative PRE results in the anti-correlation in the occurrence probability between small-amplitude and largeamplitude irregularities.

The global distribution of ESF occurrence in previous studies (Gentile et al. 2006; Kil et al. 2009; Huang et al. 2014) is similar to that of large-amplitude ESF irregularities in Fig. 9b. The characteristics of the distribution are that the ESF occurrence probability is high during equinoctial months (March, April, September, and October) and around $-60^{\circ}$ longitude in December solstice and becomes low around $\pm 60^{\circ}$ near June solstice. The high occurrence of ESF (the large-amplitude ESF irregularities in Fig. 9b) during equinoctial months is explained as the consequence of the alignment between the geomagnetic field lines and the solar terminator when sunset at the conjugate E layers is nearly simultaneous (Tsunoda 1985). The underlying physics is that the longitudinal gradient in field-line-integrated Pedersen conductivity becomes steepest, so eastward polarization electric field, corresponding to vertical plasma drift, is enhanced under the alignment condition.

As can be seen in Fig. 9a, b and as discussed above, the occurrence of large-amplitude ESF irregularities is well correlated with the PRE. This is a clear indication that the PRE is the dominant factor controlling the global distribution of occurrence of large-amplitude ESF irregularities. For the role of seeding perturbations in the ESF occurrence, Fejer et al. (1999) suggested that when the postsunset upward drift velocities are large enough, the necessary seeding mechanisms for the generation of ESF in the evening sector always appear to be present. Anderson et al. (2004) suggested that the necessary and sufficient condition for the occurrence of S4 $>0.5$ is for the postsunset upward $\mathbf{E} \times \mathbf{B}$ drift velocity to be greater than some critical value $(\sim 20 \mathrm{~m} / \mathrm{s})$ and that the seeding mechanism is always present. Su et al. (2008) found that the seasonal/longitudinal variations of the postsunset vertical ion drift track closely with those of ionospheric irregularity occurrence and that seeding perturbations from atmospheric disturbances do not show any role in the statistical results. Huang and Hairston (2015) compared the seasonal/longitudinal variations of the PRE with the variations of occurrence of small-amplitude and large-amplitude ESF irregularities, and they found that the PRE plays a controlling role in the generation of large-amplitude ESF. These studies do not exclude the existence of seeding perturbations and their role in initiating the Rayleigh-Taylor instability. Instead, it assumes that seeding perturbations in the ionosphere and atmosphere may always exist near the sunset terminator.

For solstices, Tsunoda (2010) suggested that the phase front of atmospheric gravity waves in the inter-tropical convergence zone could be aligned with the geomagnetic field lines and that large-scale wave structure, excited by deep convective activity in the troposphere, could play a significant climatological role in the generation of ESF. Tsunoda et al. (2015) examined the characteristics of ESF over Kwajalein and found that the maxima in the ESF occurrence are not aligned with the PRE. The nonalignment between the PRE and the maximum ESF occurrence was considered as indirect evidence that the PRE is not the only parameter that controls the generation of ESF. They suggested that large-scale wave structures occur most frequently during June solstice and that the tendency of high occurrence of ESF over Kwajalein during the June solstice months seems consistent with the preference for occurrence of large-scale wave structure during the same months.

It can be seen in Fig. 9b that relatively high occurrence of ESF exists in some areas/months where the PRE is small, for example, near $180^{\circ}$ longitude between March and September. In addition, the occurrence probability of ESF is also relatively high around $0^{\circ}$ longitude near June where the PRE is small. Whether large-scale wave structures or gravity waves are responsible for the relatively high occurrence of ESF in these regions/months in the $\mathrm{C} / \mathrm{NOFS}$ data needs further investigations.

\section{Conclusions}

The PRE of the postsunset vertical plasma drift is an important factor that controls the generation of ESF. A lot of efforts have been made to determine the quantitative dependence of ESF occurrence on the PRE. Different relationships between the PRE and ESF occurrence have been derived. The first one is that ESF occurs when the PRE reaches a threshold value. The threshold PRE, based mostly on measurements of ionosonde and the Jicamarca incoherent scatter radar, is typically $\sim 20 \mathrm{~m} / \mathrm{s}$ but varies with the solar radio 
flux level and season. The second relationship is that the occurrence probability of ESF increases approximately linearly with the PRE, based on measurements of the ROCSAT-1 satellite. The third relationship is that ESF occurrence probability is a continuous probability distribution as a function of the PRE, based on measurements of the C/NOFS satellite.

The three relationships are somewhat different but describe the same process. A threshold PRE for ESF occurrence is equivalent to the ESF occurrence probability of $100 \%$ when the PRE is large enough. The difference is that for a PRE of smaller than some critical value (e.g., the threshold), ESF will not occur in the relationship of threshold but may still occur at a lower probability in the relationship of probability. The linear increase of the ESF occurrence probability is based on linear regression of data in a limited range of the PRE $(0-40 \mathrm{~m} / \mathrm{s})$ and could be changed if different techniques are used for data regression and/or if the occurrence probability is calculated in a larger range of the PRE drift. For example, the continuous probability distribution is derived when the occurrence probability is calculated from the ratio of the ESF events to the total events in each $5 \mathrm{~m} / \mathrm{s}$ bin over a larger range of the PRE peak drift from -40 to $100 \mathrm{~m} / \mathrm{s}$. More events and more detailed analysis are needed to determine the occurrence of ESF as a function of the PRE in different seasons, longitudes, and solar flux levels and to determine whether the three relationships can be represented in a unified model.

The effects of seeding perturbations on the generation of ESF still need to be considered but from a different aspect. For example, in Fig. 7b, the occurrence probability of ESF is $\sim 40 \%$ for the PRE peak drift of $25 \mathrm{~m} / \mathrm{s}$. The probability of $40 \%$ means that ESF occurred in $40 \%$ of the total cases but did not occur in other $60 \%$ of the cases for this PRE value. Then, the questions are why ESF occurred in the $40 \%$ cases but not in the other $60 \%$ cases and whether the seeding perturbations in the $40 \%$ cases were statistically larger than those in the other $60 \%$ cases. We may need to analyze the amplitude of seeding perturbations at different PRE levels, rather than whether seeding perturbations exist, to determine the relative contributions of the PRE and seeding perturbations to the generation of ESF.

\section{Abbreviations \\ C/NOFS: Communication/Navigation Outage Forecasting System; DMSP: Defense Meteorological Satellite Program; ESF: Equatorial spread F; HF: High frequency; PRE: Prereversal enhancement; ROCSAT-1: The first Republic of China Satellite}

\section{Acknowledgements}

The C/NOFS mission was supported by the Air Force Research Laboratory, the SMC Defense Weather Systems Directorate, the Department of Defense Space Test Program, the National Aeronautics and Space Administration, the Naval Research Laboratory, and The Aerospace Corporation. CINDI data were provided through the auspices of the CINDI team at the University of Texas at Dallas supported by the NASA grant NAS5-01068. This work was supported in part by NASA grant NNH15AZ811.

\section{Funding}

Not applicable.

\section{Authors' contributions}

$\mathrm{CH}$ proposed the topic, outlined the article, researched the collaboration literature, and analyzed C/NOFS data. He responded to reviewer comments and then read and approved the final manuscript.

\section{Competing interests}

The author declares that he has no competing interest.

\section{Publisher's Note}

Springer Nature remains neutral with regard to jurisdictional claims in published maps and institutional affiliations.

Received: 13 June 2017 Accepted: 29 November 2017

Published online: 09 January 2018

\section{References}

Abdu MA, deMedeiros RT, Bittencourt JA, Batista IS (1983) Vertical ionization drift velocities and range type spread $F$ in the evening equatorial ionosphere. J Geophys Res 88(A1):399-402. doi:https://doi.org/10.1029/JA088iA01 p00399

Anderson DN, Reinisch B, Valladare C, Chau J, Veliz O (2004) Forecasting the occurrence of ionospheric scintillation activity in the equatorial ionosphere on a day-to-day basis. J Atmos Sol-Terr Phys 66:1567-1572

Basu S, Kudeki E, Basu S, Valladares CE, Weber E, Zengingonul HP, Bhattacharyya S, Sheehan R, Meriwether JW, Biondi MA, Kuenzler H, Espinoza J (1996) Scintillations, plasma drifts, and neutral winds in the equatorial ionosphere after sunset. J Geophys Res 101(A12):26795-26809. doi:https://doi.org/10.1029/96JA00760

Booker HG, Wells HW (1938) Scattering of radio waves by the F region of the ionosphere. J. Geophys Res 43:249-256.

Chapagain NP, Fejer BG, Chau JL (2009) Climatology of postsunset equatorial spread F over Jicamarca. J Geophys Res 114:A07307. doi:https://doi.org/10. 1029/2008JA013911

Choi JM, Kil H, Kwak YS, Park J, Lee WK, Kim YH (2017) Periodicity in the occurrence of equatorial plasma bubbles derived from the C/NOFS observations in 2008-2012. J Geophys Res Space Physics 122:1137-1145. doi:https://doi.org/10.1002/2016JA023528

Dabas RS, Lakshmi DR, Reddy BM (1998) Day-to-day variability in the occurrence of equatorial and low-latitude scintillations in the Indian zone. Radio Sci 33(1):89-96. doi:https://doi.org/10.1029/97RS02103

Dabas RS, Singh L, Lakshmi DR, Subramanyam P, Chopra P, Garg SC (2003) Evolution and dynamics of equatorial plasma bubbles: relationships to ExB drift, postsunset total electron content enhancements, and equatorial electrojet strength. Radio Sci 38:1075. doi:https://doi.org/10.1029/2001RS002586 4

Farley DT, Balsey BB, Woodman PF, McClure JP (1970) Equatorial spread F: implications of VHF radar observations. J Geophys Res 75(34):7199-7216. doi:https://doi.org/10.1029/JA075i034p07199

Fejer BG, dePaula ER, González SA, Woodman RF (1991) Average vertical and zonal F region plasma drifts over Jicamarca. J Geophys Res 96(A8):13901-13906. doi:https://doi.org/10.1029/91JA01171

Fejer BG, Jensen JW, Su S-Y (2008) Quiet time equatorial F region vertical plasma drift model derived from ROCSAT-1 observations. J Geophys Res 113:A05304. doi:https://doi.org/10.1029/2007JA012801

Fejer BG, Scherliess L, dePaula ER (1999) Effects of the vertical plasma drift velocity on the generation and evolution of equatorial spread F. J Geophys Res 104(A9):19859-19869. doi:https://doi.org/10.1029/1999JA900271

Gentile LC, Burke WJ, Rich FJ (2006) A global climatology for equatorial plasma bubbles in the topside ionosphere. Ann Geophys 24:163-172. doi:https://doi. org/10.5194/angeo-24-163-2006

Huang C-S, de La Beaujardiere O, Roddy PA, Hunton DE, Ballenthin JO, Hairston MR (2012) Generation and characteristics of equatorial plasma bubbles detected by the C/NOFS satellite near the sunset terminator. J Geophys Res 117:A11313. doi:https://doi.org/10.1029/2012JA018163

Huang C-S, de La Beaujardiere O, Roddy PA, Hunton DE, Ballenthin JO, Hairston MR, Pfaff RF (2013) Large-scale quasiperiodic plasma bubbles: C/NOFS observations and causal mechanism. J Geophys Res Space Physics 118:3602-3612. doi:https://doi.org/10.1002/jgra.50338 
Huang C-S, de La Beaujardiere O, Roddy PA, Hunton DE, Liu JY, Chen SP (2014) Occurrence probability and amplitude of equatorial ionospheric irregularities associated with plasma bubbles during low and moderate solar activities (2008-2012). J Geophys Res Space Physics 119:1186-1199. doi:https://doi.org/ 10.1002/2013JA019212

Huang C-S, Hairston MR (2015) The postsunset vertical plasma drift and its effects on the generation of equatorial plasma bubbles observed by the C/NOFS satellite. J Geophys Res Space Physics 120:2263-2275. doi:https://doi.org/10. 1002/2014JA020735

Huang C-S, Kelley MC (1996a) Nonlinear evolution of equatorial spread F: 1. On the role of plasma instabilities and spatial resonance associated with gravity wave seeding. J Geophys Res 101(A1):283-292. doi:https://doi.org/10.1029/ 95JA02211

Huang C-S, Kelley MC (1996b) Nonlinear evolution of equatorial spread F: 2. Gravity wave seeding of Rayleigh-Taylor instability. J Geophys Res 101(A1): 293-302. doi:https://doi.org/10.1029/95JA02210

Hysell DL, Kudeki E (2004) Collisional shear instability in the equatorial F region ionosphere. J Geophys Res 109:A11301. doi:https://doi.org/10.1029/ 2004JA010636

Jayachandran B, Balan N, Rao PB, Sastri JH, Bailey GJ (1993) HF Doppler and ionosonde observations on the onset conditions of equatorial spread $F$. J Geophys Res 98(A8):13741-13750. doi:https://doi.org/10.1029/93JA00302

Kelley MC (1989) The Earth's ionosphere, plasma physics and electrodynamics. Academic Press Inc., New York

Kelley MC, LaBelle J, Kudeki E, Fejer BG, Sa B, Basu S, Baker KD, Hanuise C, Argo P, Woodman RF, Swartz WE, Farley DT, Meriwether JW Jr (1986) The condor equatorial spread $F$ campaign: overview and results of the large-scale measurements. J Geophys Res 91(A5):5487-5503. doi:https://doi.org/10.1029/ JA091iA05p05487

Kelley MC, Larsen MF, LaHoz C, McClure JP (1981) Gravity wave initiation of equatorial spread F: a case study. J Geophys Res 86(A11):9087-9100. doi:https://doi.org/10.1029/JA086iA11 p09087

Kil H, Heelis RA (1998) Global distribution of density irregularities in the equatorial ionosphere. J Geophys Res 103(A1):407-417. doi:https://doi.org/10.1029/ 97JA02698

Kil H, Paxton LJ, Oh S-J (2009) Global bubble distribution seen from ROCSAT-1 and its association with the evening prereversal enhancement. J Geophys Res 114:A06307. doi:https://doi.org/10.1029/2008JA013672

Krall J, Huba JD, Joyce G, Hei M (2013) Simulation of the seeding of equatorial spread F by circular gravity waves. Geophys Res Lett 40:1-5. doi:https://doi.org/ 10.1029/2012GL054022

Li G, Ning B, Liu L, Ren Z, Lei J, Su S-Y (2007) The correlation of longitudinal/ seasonal variations of evening equatorial pre-reversal drift and of plasma bubbles. Ann Geophys 25:2571-2578

McClure JP, Singh S, Bamgboye DK, Johnson FS, Kil H (1998) Occurrence of equatorial $F$ region irregularities: evidence for tropospheric seeding. J Geophys Res 103(A12):29119-29135. doi:https://doi.org/10.1029/98JA02749

Scannapieco AJ, Ossakow SL (1976) Nonlinear equatorial spread F. Geophys Res Lett 3:451-454. doi:https://doi.org/10.1029/GL003i008p00451

Smith JM, Rodrigues FS, Fejer BG, Milla MA (2016) Coherent and incoherent scatter radar study of the climatology and day-to-day variability of mean $\mathrm{F}$ region vertical drifts and equatorial spread F. J Geophys Res Space Physics 121:1466-1482, doi:https://doi.org/10.1002/2015JA021934.

Su S-Y, Chao CK, Liu CH (2008) On monthly/seasonal/longitudinal variations of equatorial irregularity occurrences and their relationship with the postsunset vertical drift velocities. J Geophys Res 113:A05307. doi:https://doi.org/10. 1029/2007JA012809

Su S-Y, Liu CH, Ho HH, Chao CK (2006) Distribution characteristics of topside ionospheric density irregularities: equatorial versus midlatitude regions. J Geophys Res 111:A06305. doi:https://doi.org/10.1029/2005JA011330

Sultan PJ (1996) Linear theory and modeling of the Rayleigh-Taylor instability leading to the occurrence of equatorial spread F. J Geophys Res 101(A12): 26875-26891. doi:https://doi.org/10.1029/96JA00682

Thampi SV, Yamamoto M, Tsunoda RT, Otsuka Y, Tsugawa T, Uemoto J, Ishii M (2009) First observations of large-scale wave structure and equatorial spread F using CERTO radio beacon on the C/NOFS satellite. Geophys Res Lett 36: L18111. doi:https://doi.org/10.1029/2009GL039887

Tsunoda RT (1985) Control of the seasonal and longitudinal occurrence of equatorial scintillations by the longitudinal gradient in integrated $\mathrm{E}$ region Pedersen conductivity. J Geophys Res 90(A1):447-456. doi:https://doi.org/10. 1029/JA090iA01p00447
Tsunoda RT (2005) On the enigma of day-to-day variability in equatorial spread F. Geophys Res Lett 32:L08103. doi:https://doi.org/10.1029/2005GL022512

Tsunoda RT (2010) On seeding equatorial spread F during solstices. Geophys Res Lett 37:L05102. doi:https://doi.org/10.1029/2010GL042576

Tsunoda RT, Nguyen TT, Le MH (2015) Effects of tidal forcing, conductivity gradient, and active seeding on the climatology of equatorial spread $\mathrm{F}$ over Kwajalein. J Geophys Res Space Physics 120:632-653. doi:https://doi.org/10. 1002/2014JA020762

Tsunoda RT, White BR (1981) On the generation and growth of equatorial backscatter plumes 1. Wave structure in the bottomside F layer. J Geophys Res 86(A5):3610-3616. doi:https://doi.org/10.1029/JA086iA05p03610

Whalen JA (2003) Dependence of the equatorial anomaly and of equatorial spread $\mathrm{F}$ on the maximum prereversal $\mathrm{E} \times \mathrm{B}$ drift velocity measured at solar maximum. J Geophys Res 108:1193. doi:https://doi.org/10.1029/ 2002JA009755 A5

Woodman RF, La Hoz C (1976) Radar observations of F region equatorial irregularities. J Geophys Res 81(31):5447-5466. doi:https://doi.org/10.1029/ JA081i031 p05447

Zalesak ST, Ossakow SL, Chaturvedi PK (1982) Nonlinear equatorial spread F: the effect of neutral winds and background Pedersen conductivity. J Geophys Res 87(A1):151-166. doi:https://doi.org/10.1029/JA087iA01 p00151

\section{Submit your manuscript to a SpringerOpen ${ }^{\circ}$ journal and benefit from:}

- Convenient online submission

- Rigorous peer review

- Open access: articles freely available online

- High visibility within the field

- Retaining the copyright to your article

Submit your next manuscript at springeropen.com 